\title{
Health and vision related quality of life among patients with choroidal neovascular age related macular degeneration
}

\author{
Qualidade de vida relacionada com a visão em doentes \\ com degeneração macular relacionada à idade neovascular
}

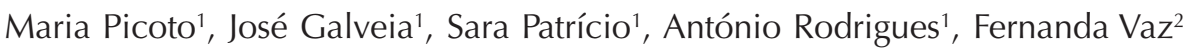

\begin{abstract}
Purpose: To describe the impact of aged-related macular degeneration (AMD) on vision-related quality of life $(Q O L)$ on a sample of portuguese patients and explore the association with vision, Central Foveal Thickness (CFT) and demographic variables in a Portuguese population. Methods: Observational, interview study of 68 patients with clinical diagnosis of NV AMD seen between January and April 2011 at the Ophthalmology Department of Centro Hospitalar de Lisboa Ocidental. Health-related quality of life (HRQL) was measured with a Portuguese version of the 25-item National Eye Institute Visual Function Questionnaire (NEIVFQ-25). Scores were analysed and correlated with age, gender, laterality of the disease, initial and final visual acuity (VA), CFT and duration of follow-up. Results: Worst eye $V A$ had predictive value in the following scores: global, distance activities, color vision, peripheral vision, role difficulties, social functioning and mental health $(p<0.05)$. In a multivariable model with inclusion of all the parameters studied, the analysed variables explained $60 \%$ of the variability of the Global Score, with a predictive value of 0.08 (R2 0.57, $p=0.088)$. Conclusion: NV AMD is associated with impairment in reported vision related QOL in our group of patients. The VA of the worst eye has a predictive value in NEIVFQ-25 scores.

Keywords: Quality of life; Macular degeneration; Visual acuity; Mental health; Questionnaires; Chronic disease
\end{abstract}

\section{RESUMO}

Objetivo: Avaliar o impacto da degeneração macular relacionada à idade (DMRI) na qualidade de vida relacionada com a visão (QVRV) numa amostra de pacientes portugueses. Métodos: Estudo observacional em corte transversal, não comparativo no qual foram incluídos 68 pacientes seguidos no Departamento de Retina Médica do Serviço de Oftalmologia do Centro Hospitalar de Lisboa Ocidental, entre Janeiro e Abril de 2011. A QVRV foi avaliada por meio do questionário National Eye Institute Visual Functioning Questionnaire (NEI-VFQ-25), traduzido para português. Os scores obtidos foram analisados e correlacionados com os seguintes parâmetros idade, sexo, lateralidade da doença, tempo de follow-up, acuidade visual (AV) e EFC iniciais e finais do melhor (MO) e pior olho (PO). Resultados: A AV do PO apresentou valor preditivo nos scores global, atividade para longe, visão cromática, visão periférica, desempenho, função social e saúde mental $(\mathrm{p}<0,05)$. Num modelo de multivariáveis com inclusão de todos os parâmetros clínicos analisados, as variáveis estudadas explicaram $60 \%$ da variância do score global (SG) com um valor preditivo de 0,08 (R2 0,57, p=0,088). Conclusões: A DMRI NV está associada a uma diminuição da QVRV. A AV do PO tem valor preditivo nos scores do NEI-VFQ-25.

Descritores: Qualidade de vida; Degeneração macular; Acuidade visual; Saúde mental; Questionário; Doença crônica

1,2 Hospital de Egas Moniz, Centro Hospitalar de Lisboa Ocidental - Lisbon, Portugal.

The authors declare no conflists of interest

Received for publication 19/05/2013 - Accepted for publication 29/09/2013

Rev Bras Oftalmol. 2015; 74 (4): 216-21 


\section{INTRODUCTION}

A ge-related macular degeneration (AMD) is the leading cause of severe vision loss in people older than 65 years ${ }^{1,2}$. Its incidence increases exponentially with age. The Framingham study ${ }^{3}$ showed an incidence of $11 \%$ in people aged between 65 and 74 years, and $30 \%$ between 75 and 85 years old. Although only 10 to $20 \%$ of AMD cases are identified as exudatively, it accounts for $80-90 \%$ of cases of blindness in this pathology ${ }^{3}$.

This disease shows a progressive loss of central vision with a measurable impact on the quality of life of the patient $t^{4}$.

When evaluating the impact of a disease, four categories of markers are considered. The physiological markers (eg: glycosylated $\mathrm{Hb}$ in Diabetes Mellitus), clinical markers (eg: VA measurement), markers reported by the clinician from their perception of the impact of the disease, and at last the markers reported by the patient.

The objective clinical measurement of the visual function in a patient such as VA provides quantitative data ${ }^{5}$. However, this analysis does not reflect the impact of the visual impairment (VI) in the daily activities (DA) of the patient. ${ }^{6}$.

The quantification of vision-related quality of life (VRQL) provides extra information on the impact of a disease in the function, particularly in the DA. This measurement is important in patients with AMD, because in addition to having high propensity to depressive disorder ${ }^{7}$, they show a VI that compromises DA and mobility, which according to Williams et al. is higher in patients of the same age and comparable to patients with chronic disease ${ }^{4}$.

The impact of VRQL on health professionals and community members is low ${ }^{8}$. Brown et al., Stein et al., Hart et al. found that these groups, including ophthalmologists, underestimate the impact of mild, moderate and severe AMD in $\mathrm{VRQL}^{9,10,11}$.

The primary objective of this study was to determine the impact of AMD NV in the vision-related quality of life (VRQL) in a sample of Portuguese patients. The secondary objectives were to understand the impact of some variables in the VRQL, namely the presence of unilateral versus bilateral diseases, the value of VA of the best and worst eye (BE and WE) and the $\mathrm{EFC}$ of the BE and WE. And finally, interpret a global model of interaction of the variables studied.

\section{MethODS}

An observational study of 68 patients followed in a retinal consultation by AMD NV between January and April 2011 in the West Lisbon Hospital. The inclusion criteria were: signing an informed consent for participation in the study; age greater than or equal to 50 years old; clinical diagnosis of AMD NV. The exclusion criteria were: follow-up of less than $6 \mathrm{~m}$; history of eye disease besides AMD which might compromise the VA (i.e., amblyopia, uncontrolled glaucoma with IOP $>30 \mathrm{mmHg}$, ischemic optic neuropathy, diabetic macular edema clinically meaningful, significant diabetic retinopathy, active uveitis, clinical signs of myopic choroiditis or refraction $>-8 \mathrm{D}$ in the current prescription; clinical evidence of thinning of the sclera.
The study participants received a questionnaire VFQ-25 translated into Portuguese during the routine consultation.

The revised parameters were as follows: age; sex; number of anti-VEGF injections performed; laterality of the disease; initial VA determined in the appointment before the treatment by the Snellen chart and by the same orthotics technician; final visual acuity assessed at the last follow-up appointment by the Snellen chart and by the same orthotics technician; EFC determined by TD OCT (Stratus, Carl Zeiss Meditec, Inc.) in two occasions.

\section{Measurement of EFC}

EFC (average thickness in 1000ìm of the core diameter) was determined using the TD OCT (Stratus, Carl Zeiss Meditec, $I n c$ ) and by a single experienced operator in the two stages. Only the scans of sufficient amount were accepted (signal strength e" 8 , cuts without areas with absent or reduced signal, core cuts in the macula and correct segmentation limits). Participants were in an iatrogenic mydriasis (pupil diameter e" $6 \mathrm{~mm}$ ) using tropicamide $0.5 \%$, and were instructed to establish an internal fixation target. After the focus adjustment was made and a good central fixation was acquired, the process started. The thickness maps were calculated from the analysis software of the appliance.

\section{Questionnaire VFQ-25}

The patients rated themselves in 12 dimensions: (1) general health; (2) overview; (3) nearsightedness; (4) activities related to farsightedness; (5) eye pain; (6) social function related to vision; (7) performance related to vision; (8) mental health related to vision; (9) dependence related to vision; (10) difficulties in driving; (11) color vision and (12) peripheral vision.

The total score ranges from 0 (worst possible function) and 100 (best possible function).

For the statistical analysis of the results we determined:

- Average age, standard deviation and distribution by age groups;

- Number of female and male patients;

- Number of patients with unilateral and bilateral disease;

- Average time of follow-up and standard deviation;

- Mean initial and final visual acuity and the respective standard deviation;

-Mean injections and standard deviation;

- Mean baseline scores for each dimension studied of the questionnaire VFQ-25 and the respective standard deviation;

- Impact of VA factors, laterality, age, sex and EFC independently in the scores of the questionnaire VFQ-25 (analysis of variance - ANOVA);

- Impact of the factors mentioned in line 8) along with the scores of questionnaire VFQ-25 (analysis of variance - ANOVA).

\section{Results}

Sixty-eight patients with AMD participated in the study conducted in medical routine appointments in the West Lisbon Hospital. The average age was 79.2 years, with $75 \%$ of the sample aged over 75 years. All patients were caucasian. Most were women $(\mathrm{n}=44)$. The final average VA of BE was $0.55 \pm 0.27$ and WE of $0.22 \pm 0.22$. The final VA of BE was e" to 0.5 in 42 patients ( $62 \%$ ), and the final VA of WE was $<0.1$ in 34 patients $(50 \%)$. The distribution of VA of $\mathrm{BE}$ and WE are listed in table 1. 
Table 1

Distribution of VA of BE and WE by subgroups

\begin{tabular}{ccccc}
\hline AV & $<\mathbf{0 . 1}$ & $\geq \mathbf{0 . 1}$ e $<\mathbf{0 . 2 5}$ & $\geq \mathbf{0 . 2 5}$ e $<\mathbf{0 . 5}$ & $\geq \mathbf{0 . 5}$ \\
\hline BE Final & $3(4 \%)$ & $8(12 \%)$ & $15(22 \%)$ & $42(62 \%)$ \\
WE Final & $34(50 \%)$ & $12(18 \%)$ & $10(15 \%)$ & $12(18 \%)$ \\
\hline
\end{tabular}

VA: visual acuity; BE: best eye; WE: worst eye

Regarding the laterality of the disease, 44 patients (68\%) had one eye disease and 21 (32\%) had bilateral disease. The average time of follow-up was $22.63 \pm 13.11$. The mean number of anti-VEGF injections per patient was $3.73 \pm 3.06$.

The scores obtained in each domain of the questionnaire VFQ-25 are described in table 2.

Table 2

\section{Scores of VRQL of NEI-VFQ 25}

\begin{tabular}{lccc}
\hline Score NEI-VFQ-25 & n & Mean (\%) & SD (\%) \\
\hline General health & 68 & 27 & 20 \\
Overview & 68 & 43 & 19 \\
Eye pain & 68 & 76 & 26 \\
Farsightedness & 68 & 51 & 26 \\
Nearsightedness & 68 & 53 & 32 \\
Social function & 67 & 66 & 36 \\
Mental health & 68 & 47 & 26 \\
Performance & 68 & 45 & 36 \\
Dependence & 68 & 77 & 28 \\
Driving & 25 & 54 & 36 \\
Color vision & 65 & 75 & 38 \\
Peripheral vision & 66 & 64 & 35 \\
Total score & 68 & 57.4 & 23 \\
\hline
\end{tabular}

Except for the score of driving, the response rate was close to $100 \%$. The highest mean values were observed in the scores of dependence $(77 \%)$, eye pain $(76 \%)$ and color vision $(75 \%)$. The lower mean scores were of general health $(27 \%)$, overview ( $43 \%$ ), performance related to vision ( $45 \%)$, mental health $(47 \%)$ and farsighted activities (53\%).

Table 3 shows the $p$-values for the impact of the VA of BE and WE independently. The results of ANOVA are presented for each one of the dimensions studied.

The VA of BE and WE explained more than $40 \%$ of the variance observed in the following scores of NEI-VFQ 25: social function related to vision $(51 \%)$, peripheral vision $(49 \%)$, performance related to vision (45\%) total score (44\%) and mental health $(42 \%)$.

In relation to the specific effect of VA of each eye in the dimensions studied, the $\mathrm{p}$-values had a statistically significant value $(p<0.05)$ for the impact of the WE in the following dimensions: peripheral vision $(\mathrm{p}=0.002)$, total score (chart 1 , $p=0.009)$, performance related to vision $(p=0.01)$, mental health $(\mathrm{p}=0.01)$, social function related to vision $(\mathrm{p}=0.01)$, nearsighted activities $(\mathrm{p}=0.02)$ and color vision $(\mathrm{p}=0.046)$. The impact of BE in the scores analyzed showed no statistical significance.
Table 3

Analysis of variance ( $p$-value) of the scores of VRQL (NEI-VFQ 25) according to the VA of BE and WE

\begin{tabular}{llccc}
\hline \multicolumn{1}{c}{$\begin{array}{c}\text { Score } \\
\text { NEI-VFQ-25 }\end{array}$} & R2 & BW (p) & WE (p) & Interaction (p) \\
\hline General health & 0.16 & 0.18 & 0.996 & 0.61 \\
Overview & 0.15 & 0.96 & 0.19 & 0.0071 \\
Eye pain & 0.1 & 0.86 & 0.35 & 0.70 \\
Farsightedness & 0.25 & 0.42 & 0.22 & 0.39 \\
Nearsightedness & 0.34 & 0.81 & 0.02 & 0.17 \\
Social function & 0.51 & 0.41 & 0.01 & 0.04 \\
Mental health & 0.42 & 0.75 & 0.01 & 0.62 \\
Performance & 0.45 & 0.79 & 0.01 & 0.16 \\
Dependence & 0.27 & 0.96 & 0.06 & 0.28 \\
Driving & 0.25 & 0.81 & 0,998 & 0.32 \\
Color vision & 0.22 & 0.42 & 0.0463 & 0.41 \\
Peripheral vision & 0.49 & 0.76 & 0.0024 & 0.05 \\
Total score & 0.44 & 0.90 & 0.0092 & 0.02 \\
\hline
\end{tabular}

\section{Chart 1}

Impact of VA of WE in the total score $(p=0.0092)$

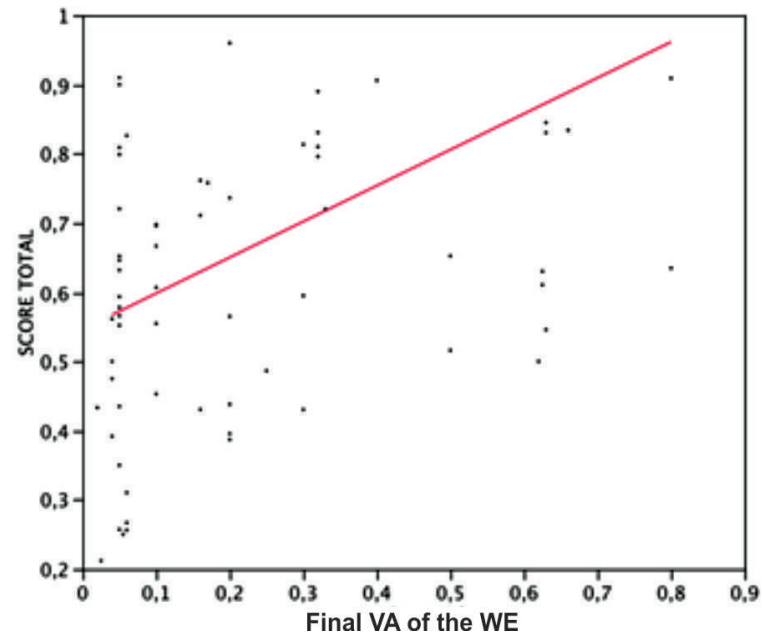

A significant interaction between the VA of $\mathrm{BE}$ and $\mathrm{WE}$ was observed in the following dimensions: overview $(p=0.007)$, social function related to vision $(\mathrm{p}=0.04)$, peripheral vision $(\mathrm{p}=0.05)$ and total score $(\mathrm{p}=0.02)$.

Regarding the laterality of the disease, patients with bilateral disease had worse results in scores except for the dimension of driving, as described in chart 2. However, the difference in value between the scores was not statistically significant. See table 4.

Regarding the study on the impact of the variable sex in the results of the scores, there was no statistically significant difference between the two sexes in the dimensions studied. Stratifying the sample by 4 age groups (group 1: < 65 years; group 2: 65-74 years; group 3: 75-84 years; group 4: 85-91 years) there was no statistically significant difference for the dimensions studied (Chart 3). 
Chart 2

\section{VRQL Scores of NEI-VFQ 25 according} to the laterality of the disease

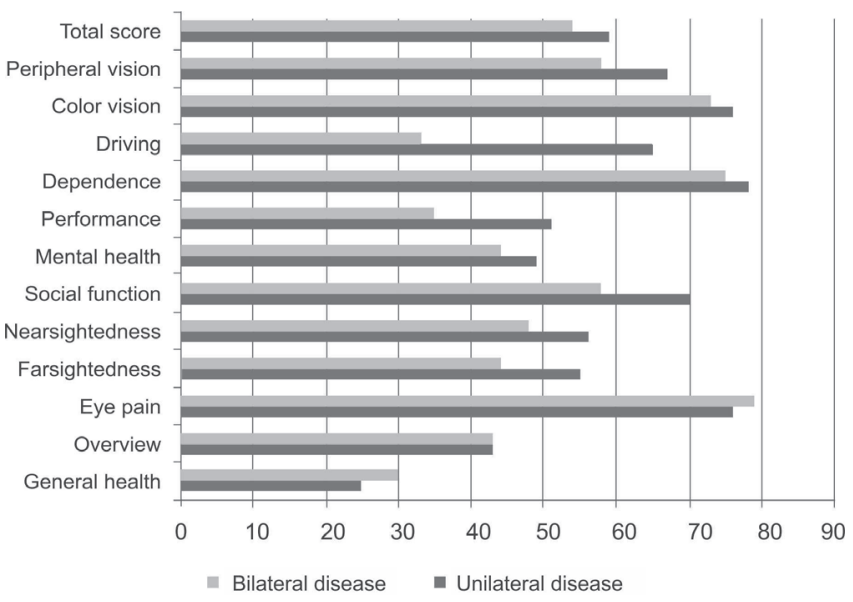

Chart 3

Analysis of variance of the total score by age groups

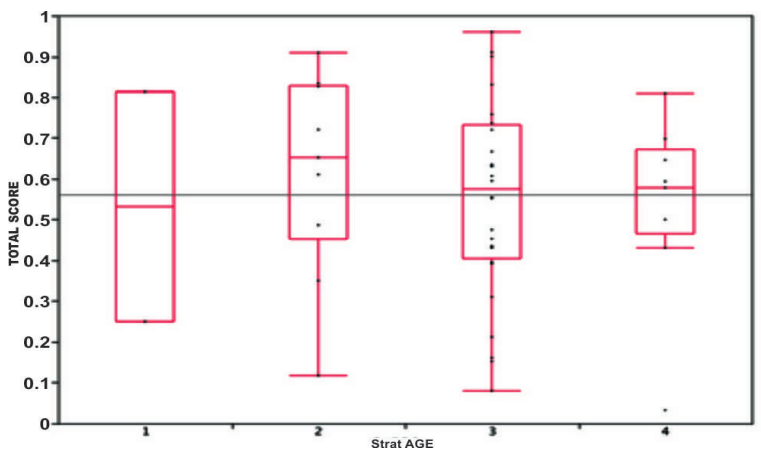

Table 4

Analysis of variance (p-value) of the scores of VRQL (NEI-VFQ 25) according to the laterality of the disease

\begin{tabular}{ccccc}
\hline $\begin{array}{c}\text { Score } \\
\text { NEI- VFQ-25 }\end{array}$ & $n$ & $\begin{array}{c}\text { Unilateral } \\
\text { disease }\end{array}$ & $\begin{array}{c}\text { Bilateral } \\
\text { disease } \\
\text { (p-value, T (student) }\end{array}$ & $\begin{array}{c}\text { Unilateral } \\
\text { /bilateral disease }\end{array}$ \\
\hline
\end{tabular}

\begin{tabular}{lcccl}
\hline General health & 68 & $25 \%$ & $30 \%$ & 0.37 \\
Overview & 68 & $43 \%$ & $43 \%$ & 0.92 \\
Eye pain & 68 & $76 \%$ & $79 \%$ & 0.68 \\
Farsightedness & 68 & $55 \%$ & $44 \%$ & 0.18 \\
Nearsightedness & 68 & $56 \%$ & $48 \%$ & 0.32 \\
Social function & 67 & $70 \%$ & $58 \%$ & 0.24 \\
Mental health & 68 & $49 \%$ & $44 \%$ & 0.54 \\
Performance & 68 & $51 \%$ & $35 \%$ & 0.102 \\
Dependence & 68 & $78 \%$ & $75 \%$ & 0.64 \\
Driving & 25 & $65 \%$ & $33 \%$ & 0.11 \\
Color vision & 65 & $76 \%$ & $73 \%$ & 0.73 \\
Peripheral vision & 66 & $67 \%$ & $58 \%$ & 0.39 \\
Total score & 68 & $59 \%$ & $54 \%$ & 0.42 \\
\hline
\end{tabular}

Analyzing the final EFC for BE and WE, a statistically significant predictive value of final $\mathrm{EFC}$ for WE was seen in the dimensions performance related to vision $(\mathrm{p}=0.03)$ and peripheral vision $(\mathrm{p}=0.03)$.

Finally, by means of the analysis of variance we assessed the impact of the variables studied in each one of the scores of VRQL. We found that the variables studied explain more than $40 \%$ of the variance of scores (Table 5).

Table 5

Analysis of variance (ANOVA) of the scores of VRQL, NEI-VFQ25 according to the variables studied

\begin{tabular}{llllllllllllll}
\hline $\begin{array}{l}\text { Score NEI } \\
- \text { VFQ-25 }\end{array}$ & $\mathbf{n}$ & $\mathbf{R 2}$ & $\begin{array}{c}\text { Age } \\
\mathbf{( p )}\end{array}$ & $\begin{array}{c}\text { Initial } \\
\text { VA of } \\
\text { BE(p) }\end{array}$ & $\begin{array}{c}\text { Initial } \\
\text { VA of } \\
\text { WE(p) }\end{array}$ & $\begin{array}{c}\text { Final } \\
\text { VA of } \\
\text { BE(p) }\end{array}$ & $\begin{array}{l}\text { Final } \\
\text { VA of } \\
\text { WE(p) }\end{array}$ & $\begin{array}{l}\text { Initial } \\
\text { EFC of } \\
\text { BE(p) }\end{array}$ & $\begin{array}{l}\text { Initial } \\
\text { EFC of } \\
\text { WE(p) }\end{array}$ & $\begin{array}{l}\text { Final } \\
\text { EFC of } \\
\text { BE(p) }\end{array}$ & $\begin{array}{c}\text { Final } \\
\text { EFC of } \\
\text { WE(p) }\end{array}$ & $\begin{array}{c}\text { No de } \\
\text { Injections }\end{array}$ & $\begin{array}{c}\text { Follow } \\
\text { - up }\end{array}$ \\
\hline General health & 68 & 0.61 & 0.51 & 0.66 & 0.03 & 0.95 & 0.26 & 0.24 & 0.60 & 0.31 & 0.0085 & 0.26 & 0.0085 \\
Overview & 68 & 0.66 & 0.3 & 0.02 & 0.92 & 0.11 & 0.41 & 0.33 & 0.15 & 0.18 & 0.89 & 0.64 & 0.64 \\
Eye pain & 68 & 0.4 & 0.54 & 0.59 & 0.33 & 0.14 & 0.09 & 0.19 & 0.57 & 0.18 & 0.4 & 0.67 & 0.35 \\
Farsightedness & 68 & 0.63 & 0.3 & 0.0063 & 0.66 & 0.42 & 0.87 & 0.33 & 0.07 & 0.36 & 0.57 & 0.39 & 0.33 \\
Nearsightedness & 68 & 0.63 & 0.28 & 0.00 & 0.61 & 0.14 & 0.31 & 0.03 & 0.93 & 0.03 & 0.04 & 0.87 & 0.067 \\
Social function & 67 & 0.53 & 0.46 & 0.04 & 0.76 & 0.07 & 0.27 & 0.45 & 0.24 & 0.24 & 0.34 & 0.71 & 0.11 \\
Mental health & 68 & 0.4 & 0.56 & 0.09 & 0.99 & 0.64 & 0.6 & 0.16 & 0.71 & 0.12 & 0.47 & 0.82 & 0.28 \\
Performance & 68 & 0.46 & 0.57 & 0.15 & 0.96 & 0.11 & 0.83 & 0.52 & 0.9 & 0.27 & 0.87 & 0.34 & 0.87 \\
Dependence & 68 & 0.67 & 0.16 & 0.0032 & 0.3194 & 0.9771 & 0.0069 & 0.116 & 0.72 & 0.08 & 0.445 & 0.850 & 0.011 \\
Color vision & 65 & 0.38 & 0.14 & 0.15 & 0.84 & 0.78 & 0.84 & 0.18 & 0.78 & 0.11 & 0.96 & 0.57 & 0.95 \\
Peripheral vision & 65 & 0.58 & 0.4 & 0.11 & 0.17 & 0.1 & 0.2 & 0.41 & 0.2 & 0.15 & 0.26 & 0.57 & 0.09 \\
Total score & 68 & 0.6 & 0.37 & 0.0076 & 0.71 & 0.27 & 0.3 & 0.16 & 0.21 & 0.09 & 0.36 & 0.86 & 0.37 \\
\hline
\end{tabular}


This model built from the analysis of multivariate variance explains $60 \%$ of the variance of the total score, with a predictive value of 0.08 (Chart 4).

\section{Chart 4}

\section{Analysis of variance of the total score (total score $=$ - $0.773+0.0076$ age +0.0076 No. inj +0.625 VA BE +0.032 VA WE + 0.271 VA BE - 0.287 VA WE - 0.001 EFCi BE + 0.001 EFCi WE + 0.0016 EFC BE + 0.003 EFC WE)}

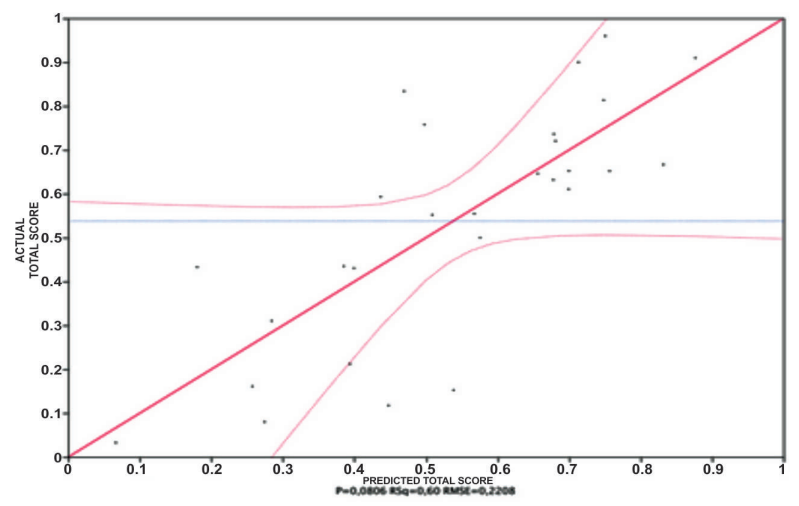

\section{Discussion}

The demographic characteristics of the sample, $75 \%$ of patients over 75 years old and predominance of females, are in accordance with the normal distribution of a population of patients with $\mathrm{AMD}^{12}$.

The results of the study clearly show that the VA has a greater impact on VRQL, a finding already documented in other studies $^{7,8}$. Regarding the use of the questionnaire NEI-VFQ 25 as a way of measuring the VRQL, to date several researchers have consistently found associations between low VA and low VRQL using this assessment tool ${ }^{5,13}$.

This effect is particularly important in QOL in elderly patients, to the extent that it leads to dependence, disability, anxiety and depression. Some areas were more affected than others by the VA. The impact was virtually non-existent in eye pain $(\mathrm{R} 2=0.1)$ and in general health $(\mathrm{R} 2=0.15)$, unlike the domains of social function related to vision $(\mathrm{R} 2=0.51)$, peripheral vision $(\mathrm{R} 2=0.49)$, performance related to vision $(\mathrm{R} 2=0.45)$, total score $(\mathrm{R} 2=0.44)$ and mental health $(\mathrm{R} 2=0.42)$, in which the impact was pretty strong.

This result is consistent with previous studies ${ }^{4}$. The symptomatic profile of the disease, in which there is a progressive loss of the central vision, explains the changes reported by the patients in activities that rely on it, including reading labels of medicines and daily shopping at the supermarket. The low scores on mental health, social function and performance related to vision show the insulating effect of this disease and reflect the loss of independence and increased anxiety.

It was observed that the VA of the WE had a higher predictive value than the VA of the $\mathrm{BE}$ in the following scores on the questionnaire: peripheral vision, total score, performance related to vision, mental health, social function, nearsighted activities and color vision. This finding is supported by several studies described in the literature.
In the study of Berdeaux ${ }^{8}$ et al., the VA of the WE had a measurable impact on mental health, dependence, color vision and farsightedness.

In the Los Angeles Latino Eye Study ${ }^{14}$, patients with VA in the WE $<20 / 200$ had worse scores in all dimensions, except for general health and eye pain.

According to the study by Azen et al. ${ }^{15}$ both eyes contribute independently to the VRQL, and the preservation of a minimal VA in the WE may contribute to the VRQL.

Moreover, patients with worse views, even if only in one of the eyes and without reflection on binocular vision, had higher rates of depression, which has an impact on the VRQL, as reported by several researchers ${ }^{4,7}$.

The findings in the aforementioned studies confirm previous publications on the influence of VA of the WE on the VRQL in ophthalmic diseases. The final impact of VA of the WE was initially demonstrated in articles about the benefits of cataract surgery in the second eye $\mathrm{e}^{14}$. Subsequent articles have confirmed these results to other ophthalmic pathologies characterized by chronic loss of visual function, particularly gaucoma, AMD and uveitis.

The impact of VA of the WE can be explained by the phenomenon of visual inhibition, where binocular vision is worse than the vision of the BE in 1 or more lines. The Los Angeles latino Eye Study ${ }^{14}$ demonstrated that a high proportion of individuals may be affected by this phenomenon. Thus the evaluation of binocular vision should be a primary measure in the study of vision difficulties, since it reflects the usual mode of operation.

In this study, it was observed that the impact of unilateral and bilateral disease in VRQL was comparable. That is, in spite of the VRQL scores in patients with bilateral disease are lower than in patients with unilateral disease, there was no difference between these two groups, both having similar effects on the VRQL. This finding has several implications. Given the current economic situation, sometimes the treatment of AMD NV in a second eye has to be considered, especially when the VA if it is very low and worse than the 1 st eye treated. The decision may be not treating the 2nd eye if the greatest improvement of VA and VRQL occurs after the treatment of the first eye. In this study, since it was observed that the unilateral disease has an impact similar to the bilateral disease and that the VA of the WE has a greater impact on the VRQL, treating the second eye may be recommended, even though it has a VA worse than the first eye treated. These findings were also described by Varma et al. ${ }^{5}$, and Javitt et al. ${ }^{16,17}$ regarding other ocular pathology, cataracts.

From the multivariable model with inclusion of all clinical parameters analyzed, it was found that the variables studied explain $60 \%$ of the variance of the global score (GS) with a predictive value of 0.08 (R2 0.57, p 0.088). However, individually basis the variables age and sex don't explain the variance of scores, such as the EFC for most scores. These results are important, given that age and sex are often factors that confuse the analysis of QOL, which was not the case in our sample. Regarding the EFC, this is an anatomical measurement and that often has no correlation with the functional aspects, particularly when a psychosocial functional dimension is assessed. Furthermore, despite the AMD the value of EFC can be high or low in patients with low VA, either by intraretinal edema or by atrophy of the retinal layers.

Currently, the treatment of AMD tends to preserve mostly the vision and entails heavy financial burden. The cost-benefit 
analysis is essential in the decision to treat a patient with NV. The evaluation of VRQL may be an extra tool in the decision-making for both the beginning as for the maintenance of the therapy in case this translates into an improved VRQL.

This study has several limitations, including the sample size and the age of the patients, which may put some bias in the application of a questionnaire. In addition, the sample was not controlled for the degree of differentiation.

The VRQL of patients with NV, assessed by NEI-VFQ 25, reveals an association to the VA of the patient. Unilateral and bilateral diseases have similar impact on the VRQL. The preservation of the VA in the WE is important in maintaining the VRQL. This study suggests that the WE should be treated for maintaining a good long-term VRQL. The assessment of the VRQL should be included in future studies aimed at a better understanding of the impact of this disease on patients' lives and a better assessment of the effect of the treatment of this disease.

\section{ReFERENCES}

1. Klein R, Klein BE, Linton KL. Prevalence of age-related maculopathy. The Beaver Dam Eye Study. Ophthalmology. 1992;99(6):933-43.

2. Vingerling JR, Dielemans I, Hofman A, Grobbee DE, Hijmering M, Kramer CF, et al. The prevalence of age-related maculopathy in the Rotterdam Study. Ophthalmology. 1995;102(2):205-10.

3. Leibowitz HM, Krueger DE, Maunder LR, Milton RC, Kini MM, Kahn HA, Nickerson RJ, Pool J, Colton TL, Ganley JP, Loewenstein JI, Dawber TR. The Framingham Eye Study monograph: An ophthalmological and epidemiological study of cataract, glaucoma, diabetic retinopathy, macular degeneration, and visual acuity in a general population of 2631 adults, 1973-1975. Surv Ophthalmol. 1980;24(Suppl):335-610.

4. Williams RA, Brody BL, Thomas RG, Kaplan RM, Brown SI. The psychosocial impact of macular degeneration. Arch Ophthalmol. 1998;116(4):514-20.

5. Varma R, Wu J, Chong K, Azen SP, Hays RD; Los Angeles Latino Eye Study Group. Impact of severity and bilaterality of visual impairment on health-related quality of life. Ophthalmology. 2006;113(10):1846-53.

6. Margolis MK, Coyne K, Kennedy-Martin T, Baker T, Schein O, Revicki DA. Vision-specific instruments for the assessment of health-related quality of life and visual functioning: a literature review. Pharmacoeconomics. 2002;20(12):791-812. Review.
7. Brody BL, Gamst AC, Williams RA, Smith AR, Lau PW, Dolnak $\mathrm{D}$, et al. Depression, visual acuity, comorbidity, and disability associated with age-related macular degeneration. Ophthalmology. 2001;108(10):1893-900; discussion 1900-1.

8. Berdeuax GH, Nordmann JP, Colin E, Arnould B. Vision-related quality of life in patients suffering from age-related macular degeneration. Am J Ophthalmol. 2005;139(2):271-9.

9. Brown GC, Brown MM, Sharma S. Difference between ophthalmologists' and patients' perceptions of quality of life associated with age-related macular degeneration. Can J Ophthalmol. 2000;35(3):127-33.

10. Stein JD, Brown MM, Brown GC, Hollands H, Sharma S. Quality of life with macular degeneration: perceptions of patients, clinicians, and community members. Br J Ophthalmol. 2003;87(1):8-12.

11. Hart PM, Chakravarthy U, Stevenson MR. Questionnaire-based survey on the importance of quality of life measures in ophthalmic practice. Eye (Lond). 1998;12(Pt 1):124-6.

12. Delcourt C. Epidemiology of AMD. In: Silva R., coordinator. AMD Age-related macular degeneration. GER Group; 2010. p.11-20.

13. Cahill MT, Banks AD, Stinnett SS, Toth CA. Vision-related quality of life in patients with bilateral severe age-related macular degeneration. Ophthalmology. 2005;112(1):152-8.

14. Globe DR, Wu J, Azen SP, Varma R; Los Angeles Latino Eye Study Group. The impact of visual impairment on self-reported visual functioning in Latinos: The Los Angeles Latino Eye Study. Ophthalmology. 2004;111(6):1141-9.

15. Azen SP, Varma R, Preston-Martin S, Ying-Lai M, Globe D, Hahn S. Binocular visual acuity summation and inhibition in an ocular epidemiological study: the Los Angeles Latino Eye Study. Invest Ophthalmol Vis Sci. 2002;43(6):1742-8.

16. Javitt JC, Steinberg EP, Sharkey P, Schein OD, Tielsch JM, Diener $\mathrm{M}$, Cataract surgery in one eye or both. A billion dollar per year issue, Ophthalmology. 1995;102(11):1583-92

17. Javitt JC, Brenner MH, Curbow B, Legro MW, Street DA, Outcomes of cataract surgery. Improvement in visual acuity and subjective visual function after surgery in the first, second, and both eyes, Arch Ophthalmol. 1993;111(5):686-91.

\section{Corresponding author:}

Maria Picoto

Rua: Silva e Albuquerque, 15, rc dto,

Zip Code: 1700-360, Lisbon, Portugal.

E-mail: picoto.maria@gmail.com, 